\title{
SUPPLIER ENVIRONMENTAL PERFORMANCE EVALUATION USING AHP
}

\author{
Richard Y. K. Fung and Caroline F. Y. Wong \\ Department of Manufacturing Engineering and Engineering Management \\ City University of Hong Kong \\ 83 Tat Chee Avenue, Kowloon, Hong Kong \\ meykfung@cityu.edu.hk
}

Keywords: supplier performance, environmental supply chain management

\begin{abstract}
Summary: Supplier evaluation is an essential purchasing functions, and prerequisite for effective supply chain management. Traditional supplier selection criteria include price, quality, delivery, and service. Recent customer requirements, competitive pressures, legislation and resource conservation and sustainability opportunities have motivated companies to give their environmental performance a higher priority. However, many organizations still consider operating environmentally means higher costs, just like what they once thought about quality improvement. This paper explores how cost savings and new opportunities can be gained through implementing environmental initiatives in supply chain management using an AHP-based model for supplier evaluation. In order to identify supplier environmental performance indicators and facilitate continuous improvement in this area, a supplier evaluation and benchmarking model is proposed. The model framework is based on the logical extension of the ISO 14031-Environmental Performance Evaluation (EPE) guidelines, taking a Deming's Plan-Do-Check-Act (PDCA) approach to bring continuous improvements. An AHP-based routine is used to conduct the suppliers evaluation and benchmarking process.
\end{abstract}

\section{Introduction}

Literatures reveal that environmental management is becoming an integral part of business strategy driven by customer requirements, competitive pressures, government regulations and legislation, and resource conservation opportunities and so on. In addition, Hanna and Newman (1994) note that customers, both industrial and consumer, have become more environmentally conscious in recent years. The increasing general awareness of environmental management systems (EMS), such as BS 7750, ISO 14001 or the EU's Eco-Management and Audit Scheme (EMAS), have made companies become more environmentally proactive. This trend is set to accelerate with escalating public pressures.

This paper describes the design and application of the proposed Supplier Environmental Performance Evaluation (SEPE) model to benchmark suppliers' environmental performance with a view to bringing about continuous improvement. The aim of this SEPE model is to help companies gain competitive advantages through:

- $\quad$ Selecting meaningful environmental performance indicators;

- Benchmarking the environmental performance among suppliers using AHP;

- Facilitating continuous improvement on the performance through P-C-D-A iterations; and

- Assisting in building and implementing environmental management systems along one's supply chain or value chain.

\section{Potential Benefits and Opportunities from Environmental Supply Chain Management}

Enarsson (1997) suggests that companies of today do not necessarily have a dilemma between satisfying the needs for environmental concerns and profitability. However, Denton (1998) reports that many businesses still consider environmental improvement being a cost center, just like what they once did with quality. It is true that the environmental performance like quality may incur some initial shortterm costs, but in the long run, the benefits and savings resulting from sound environmental practices would outweigh the initial investment. Denton believes that companies that see the environment as a cost rather than a chance to gain a competitive advantage are perhaps missing the best opportunity of 
this decade. In 1980s, quality was the vehicle that delivered greater profits and market share, but many businesses were late to recognise that quality is in fact a profit spinner rather than a liability. It was only the success of the Japanese and consumer pressure that created the quality revolution. In the 2000 s, it is the environment that holds enormous potential for business.

In fact, a company can utilize their environmental programs to reduce all round manufacturing costs. According to Klassen (1993), there are two types of environmental costs, i.e. the cost for improving the environmental performance, and the cost of neglecting the need for operating environmentally. The former includes the costs of training for sound environmental management and the facilities for preventing, monitoring, auditing and controlling pollution. The latter includes the cost of not meeting stakeholder requirements, the cost of non-conformance (eg. fines, increasing liability insurance, and clean-up expenses), the cost of lost opportunities from negative public relations, and the uncertain cost of potential future liabilities. It is true that the sooner an organization treat the environmental challenge as a competitive opportunity, the more likely it is to benefit from it.

In recent years, a number of researchers and practitioners have reported that the green wave offers a company opportunities to add value through use of renewable resources, minimal environmental impact of raw materials extraction, use of non-endangered species and reduce impacts when raw materials are transported to the production center. Well-developed efforts, such as pollution prevention, recycling, and energy conservation programs, are already the norm throughout industry as a mechanism to control these costs (Bhat, 1998; Denton, 1998; Enarsson, 1997; Kinlaw, 1993; Blumenfeld, 1992). Consequently, cost savings and new opportunities from environmental initiatives are feasible.

As Hoek (1999) suggests, a more far-reaching approach, value seeking, should be adopted in environmental management with strategic commitment, supply chain initiative, supplier partnership and so on. Supplier environmental management has started to emerge as a theme in response to new international standards and regulations.

\section{Supplier Environmental Performance Evaluation (SEPE)}

Nowadays, some proactive companies have been evaluating suppliers on their environmental consciousness. Craig (1997), Green et al. (1998), HKPC (1996) and Knight (1995) show examples of Environmental Conscious Supplier (ECS) evaluation processes. Case studies on the ECS evaluation in four international companies, namely B\&Q, British Telecom, The Body Shop and Sun Microsystems Incorporation, discussed by Fung et al., (1999) (see Table 1) form a good basis for the SEPE model described in this paper.

Table 1: Comparison of ECS evaluation systems of selected international companies

\begin{tabular}{|c|c|c|}
\hline Company & Evaluation Expectations & Evaluation Media \\
\hline B\&Q & $\begin{array}{ll}\text { - } & \text { Safety and integrity of the product } \\
\text { - } & \text { Supplier's quality performance } \\
\text { - } & \text { Supplier's environmental policy } \\
\text { - } & \text { Supplier's record on environmental actions } \\
\text { - } & \text { Supplier's claims on packaging and other } \\
& \text { environmental issues } \\
\end{array}$ & $\begin{array}{ll}\text { - } & \text { QUEST system Questionnaire } \\
\text { - } & \text { Site visit } \\
\text { - } & \text { Additional correspondence } \\
\text { - } & \text { (Grades range from A to F) }\end{array}$ \\
\hline The Body Shop & $\begin{array}{ll}\text { - } & \text { Environmental management } \\
\text { - } & \text { Auditing practices }\end{array}$ & $\begin{array}{ll}\text { - } & \text { Environmental Rating Scheme } \\
\text { - } & \text { (Initial questionnaire: 0-2 stars) } \\
\text { - } & \text { (Detailed questionnaire: } 3-5 \\
& \text { stars) } \\
\end{array}$ \\
\hline British Telecom & $\begin{array}{ll}\text { - } & \text { Environmental insurance and compliance } \\
\text { - } & \text { Internal quality standards } \\
\text { - } & \text { Environmental policy } \\
\end{array}$ & - Questionnaire \\
\hline $\begin{array}{l}\text { Sun Micro- } \\
\text { systems, Inc. }\end{array}$ & $\begin{array}{l}\text { - } \text { Quality, delivery, flexibility and lead-time } \\
\text { - } \quad \text { Environmental efforts }\end{array}$ & $\begin{array}{l}\text { - Suppliers earn points for } \\
\text { positive performance and have } \\
\text { pints subtracted for } \\
\text { substandard performance } \\
\text { - } \quad \begin{array}{l}\text { Suppliers can earn up to a total } \\
\text { of } 100 \text { points }\end{array}\end{array}$ \\
\hline
\end{tabular}




\subsection{Development of an AHP-based SEPE model}

In this research, a model is designed and developed with reference to the Deming's PDCA concept and a logical extension of the ISO 14031-EPE standard. Figure 1 shows the overall implementation process flow of the proposed SEPE methodology. This model is applicable to any organization that wishes to establish and implement an environmental purchasing strategy (EPS) with a view to assuring that suppliers operate in conformance with their stated environmental policy, and facilitating continuous improvement in relevant areas. The extent to which the proposed procedures are followed depends on such factors as the environmental policy of the organization, the nature of the materials purchased as well as the circumstances and local legislation in which the suppliers operates.

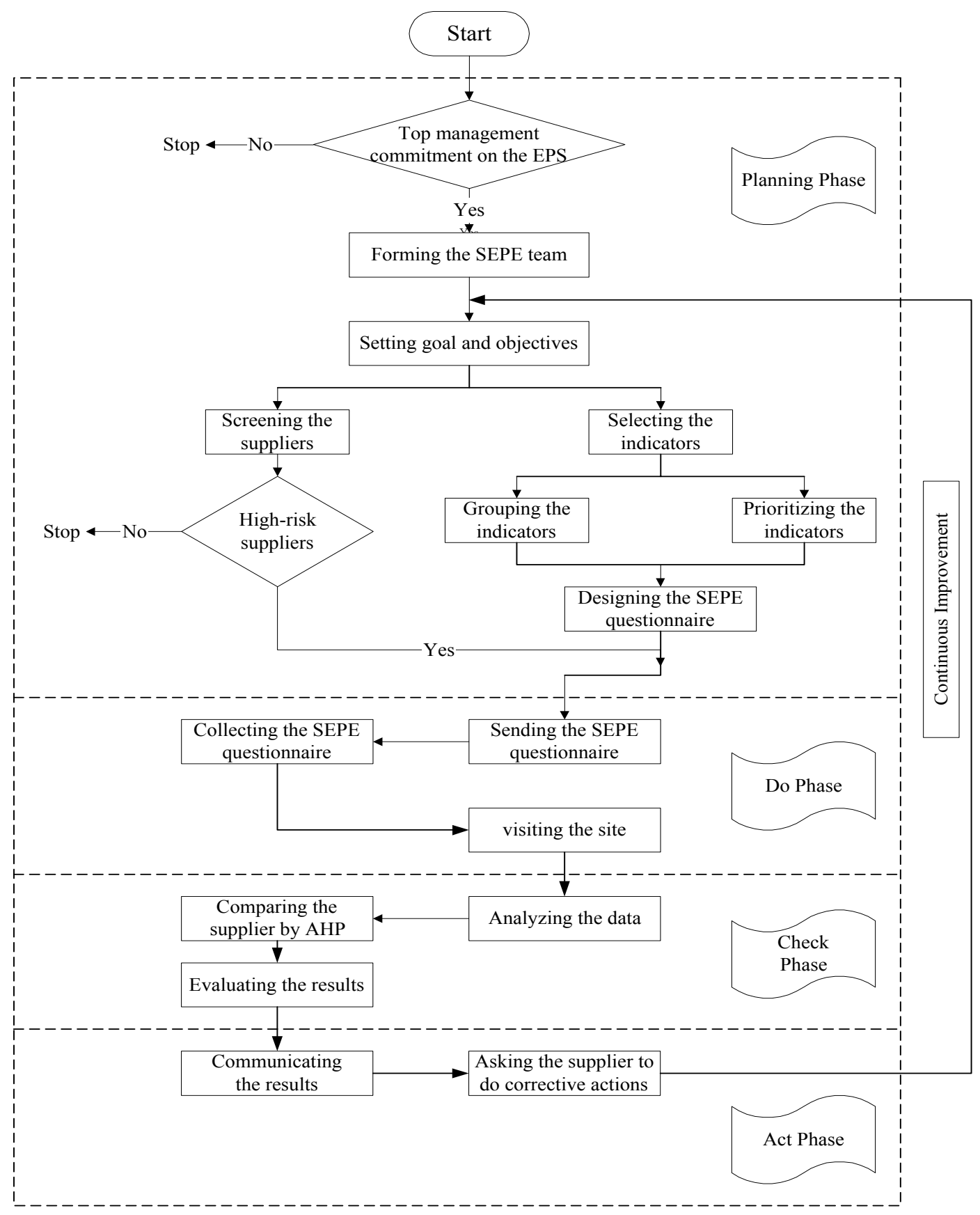

Figure 1 The proposed SEPE model 


\subsubsection{The Plan Phase}

\section{a) Getting Management Commitment}

Planning in the SEPE process involves reviewing or identifying those environmental aspects of the supplier activities, products and services that have generated environmental purchasing objectives and targets. Support of the SEPE by top management should be obtained very early in the process.

\section{b) Forming the SEPE Team and Fixing the Terms of Reference}

Once the top management is committed to the SEPE approach, a team is then formed with a well defined set of goal and objectives in order to guide its operations.

\section{c) Identifying High-Risk Suppliers}

To evaluate the environmental impacts of every supply chain activities would be expensive and impractical, targeted suppliers which are more likely to affect the overall environmental performance of the entire supply chain have to be identified. The scale and nature of the suppliers' operations, products and services, and the size and importance of the contracts concerned are among the factors to be considered while deciding whether a supplier belongs to the high risk category.

\section{d) Determining the Supplier Environmental Performance Indicators (SEPI)}

The SEPE process should concentrate on the selection of environmental performance indicators (EPI). A very critical part of the SEPE process should be to determine the meaningful indicators which can readily reflect how the suppliers perform environmentally(Lee, 1998). Eagan and Joeres (1997) claim that companies are increasingly interested in using EPI to gauge how well their environmental goal and objectives are met. In addition, Wathey (2000) suggests that SEPI is a more cost effective supplier evaluation tool than what has generally been applied. It allows the measurement of tangible and significant aspects of environmental performance at a given point or over time.

One of the purposes of SEPE is to determine whether the supplier's environmental performance meets the company's environmental purchasing goal and objectives. The cause-and-effect diagram or the fish-bone diagram is a practical means for tracing the figure out the factors affecting the supplier environmental performance as illustrated in Figure 2.

\section{e) Setting the Questionnaire}

Once the factors affecting suppliers' environmental performance have been identified, design of questionnaire will follow. The questionnaire can serve as a means of understanding suppliers' current environmental activities with a view to soliciting and disseminating the best practice among other supply chain practitioners.

\subsubsection{The Do and Check Phases}

The Do phase involves the measurement and collection of data through questionnaire and site visit. Evaluation measurement allows an organization to better understand and quantify where their suppliers are in relation to their environmental purchasing objectives and targets. It also provides a basis for determining the requirements for improvement. The data captured can help determine the values for respective SEPI.

During the Check phase, the data are analysed and evaluated to help extract useful information concerning the supplied material's impact on the environment. The SEPE team can thus determine whether the supplier meets all or part of the environmental metrics. If a supplier is found performing environmentally badly, the evaluation step should also highlight ways to help them improve.

A good evaluation should be as fair and objective as possible. In this model, an additional methodology is needed to capture both the fair and objective evaluation measures. As discussed before, the AHP makes the supplier selection process possible to quantify the intangible factors in a more elaborate way than in the conventional subjective manner. Apart, AHP is a suitable approach for determining both the importance of weights for indicators and the relative ranking of a number of alternatives.

\section{a) Hierarchical Structure (Step 1)}

In order to develop objectivism, the SEPE team should follow the AHP-based procedure as shown in Figure 3 to check the supplier's environmental performance. The first step of the AHP-based procedure 
is the construction of a hierarchical structure which can be converted from the fish-bone diagram presented in Figure 2 to evaluate supplier's environmental performance as shown in Figure 4.

b) Relative Importance of the Indicators and Sub-indicators (Step 2)

In this stage, the SEPE team should do a pairwise comparison towards the indicators and subindicators. Later on, with the help of the software package, Expert Choice, the importance ratings for individual indicators with the inputs from pairwise comparisons are calculated. Once the pairwise comparisons are obtained from the SEPE team, the relative weights (wi/wj) of the level 1 attributes are computed as shown in Figure 5.

\section{c) Environmental Performance of the Supplier (Step 3 to Step 5)}

With the help of filled questionnaire which collected from the Do phase, in step 3, the SEPE team should able to identify the quantitative measures or qualitative evaluations that describe the extent to which each supplier achieves the sub-indicators and enter their judgement into the Expert Choice.

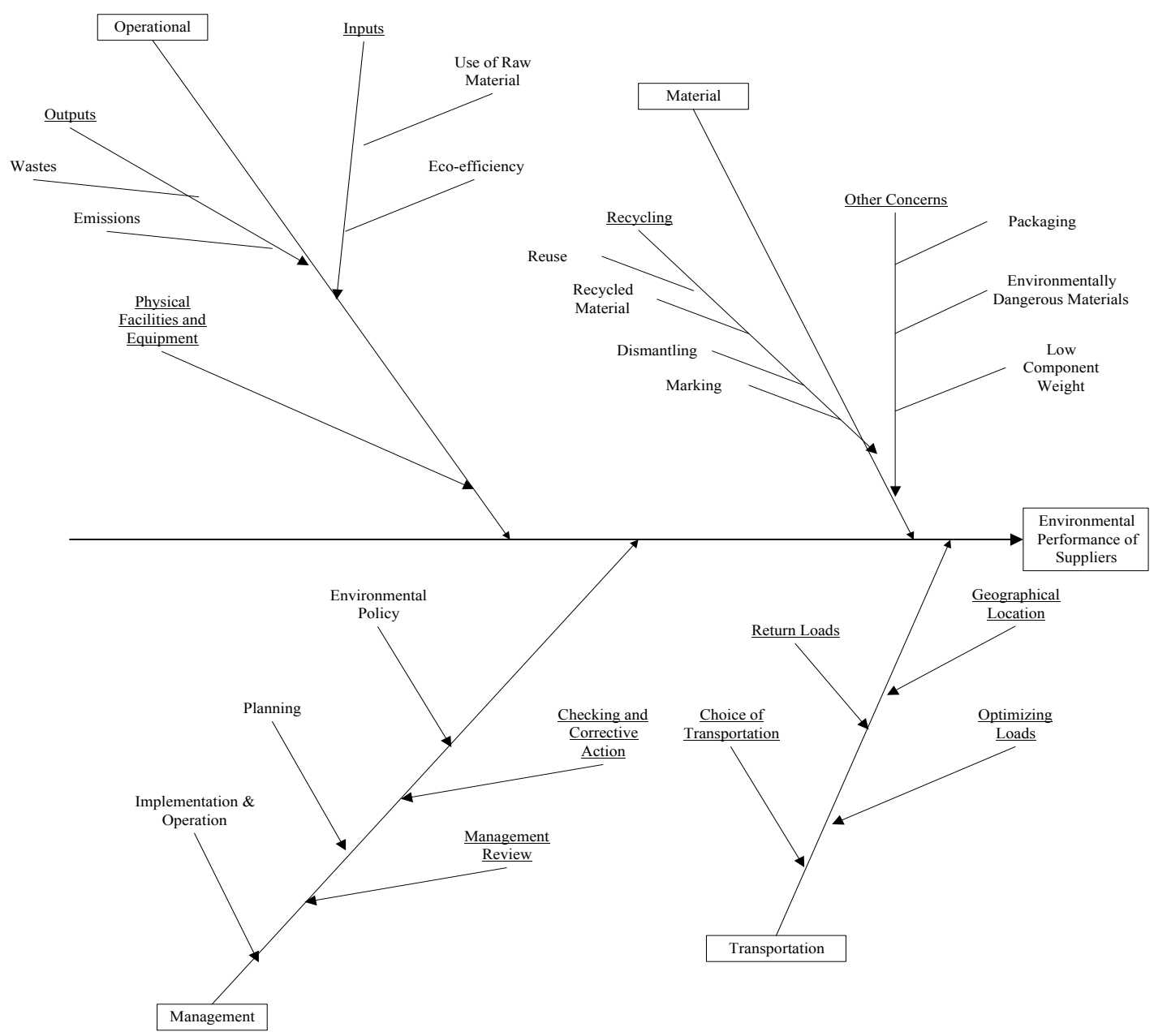

Figure 2 A cause-and-effect / fishbone diagram for determining the key factors affecting suppliers' environmental performance 
Figure 3: AHP-based procedure for SEPE

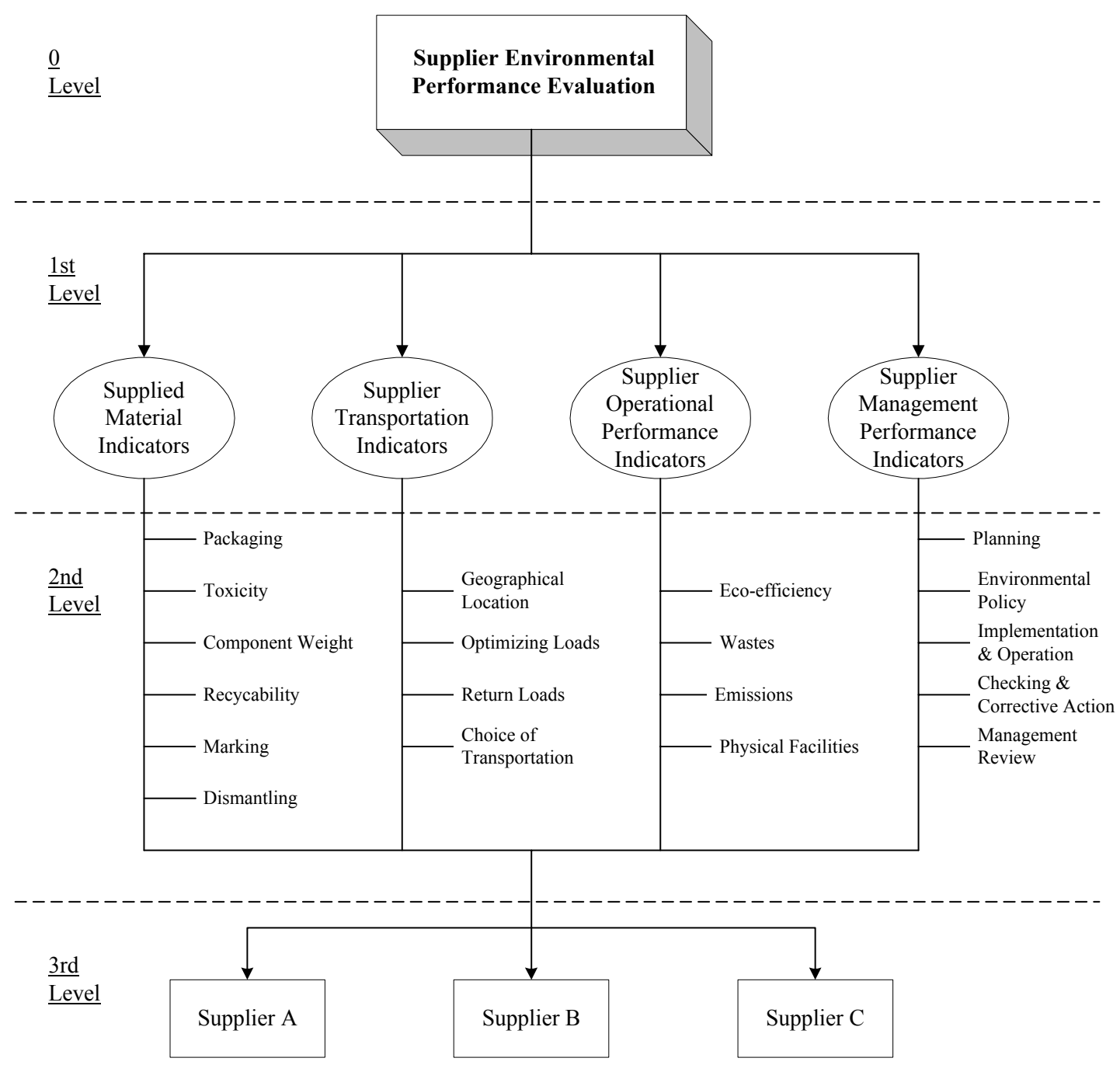

Figure 4 Hierarchical structure of the SEPE model

\begin{tabular}{|c|c|c|c|c|c|}
\hline & SMTIs & STPIs & SOPIs & SMPIs & $\begin{array}{l}\text { Normalized } \\
\text { Row Average }\end{array}$ \\
\hline SMTIs & 1 & & \multirow{2}{*}{\multicolumn{2}{|c|}{$\begin{array}{l}\text { Reciprocals of entries } \\
\text { below the diagonal }\end{array}$}} & W1 \\
\hline STPIs & w1/w2 & 1 & & & W2 \\
\hline SOPIS & w1/w3 & w2/w3 & 1 & & W3 \\
\hline SMPIs & w1/w4 & w2/w4 & w3/w4 & 1 & W4 \\
\hline
\end{tabular}




\section{Figure 5 Pairwise comparison matrix for level 1 of the SEPE model}

\subsubsection{The Act Phase}

If the data from previous phases are used to make meaningful environmental improvements, the results have to be clearly communicated to the suppliers. During SEPE, it may be found that the supplier's performance does not meet the corresponding target or objectives or they are less competitive than other suppliers. The root causes of the problems will be identified and acted upon accordingly.

\section{Conclusions}

This paper describes an environmental initiatives in developing and implementing an SEPE model for measuring how well suppliers perform against key environmental indicators as well as the corresponding performance of other suppliers in the market. The model allows buyers to effectively benchmark their suppliers' environmental performance with that of the "best suppliers" on list, with the help of AHP-based evaluation procedures. The results from the exercise will form the basis for negotiations with the under-performers in order to set targets for continuous improvement.

\section{References}

Bhat (1998) “Total Quality Environmental Management” Quorum Books, Westport, Connecticut, London.

Blumenfeld, K. (1992) “Managing the Product Life Cycle", Management Review, Vol. 80, No. 3, pp. 30-31

Craig, E. (1997) "Integrating environmental considerations into supplier management processes at Sun Microsystems, Inc.", IEEE International Symposium on Electronics \& the Environment, pp. 282-284

Denton, D.K. (1998) "Enviro-management as a profit center" Environmental Management and Health, 9/2, pp. 60-64

Eagan, P.D. and Joeres, E. (1997) "Development of a facility-based environmental performance indicator related to sustainable development", J. Cleaner Prod., Vol. 5, No. 4, pp. 269-278

Enarsson, L. (1997) "Evaluation of suppliers: how to consider the environment" International Journal of Physical Distribution \& Logistics Management, Vol. 28, No. 1, pp. 5-17

Fung, Y.K., Wong, F.Y. and Pun, K.F. (1999) "Environmentally conscious purchasing: an overview of international practices" Proceedings of the Fourth International Conference on ISO 9000 \& TQM, pp. 201-206

Green, K., Morton, B. and New, S. (1998) "Green purchasing and supply policies: do they improve companies' environmental performance?”, Supply Chain Management, Vol. 3, No. 2, pp. 89-95

Hanna, M.D. and Newman, W.R. (1994) "Operations and environment: an expanded focus for TQM", International Journal of Quality \& Reliability Management, Vol. 12, No. 5, pp. 38-53

HKPC, (1996) "Supplier auditing - the next step in effective environmental management", Green Productivity, March, pp. 12-16

Hoek, R.I. (1999) "From reversed logistics to green supply chains", Supply Chain Management, Vol. 4, No. 3, pp. 129-134

Kinlaw, D.C. (1993) "Competitive \& green: sustainable performance in the environmental age", Pfeiffer \& Company, London.

Klassen, R.D. (1993) "The integration of environmental issues into manufacturing: toward an interactive open-systems model", Production and Inventory Management, Vol. 34, No. 1, pp. 82-88

Knight, A. (1995) "B\&Q, its suppliers an the environment", Industry and Environment, April September, pp. 32-34

Lee, K.W. (1998) “ISO 14031 Environmental Performance Evaluation (EPE)”, Prentice Hall PTR, Upper Saddle River

Wathey, D. (2000) “Environmental Supply Chain Management", http://www.14001.com/articles/escmwathey.html 
